\title{
Unusually stable abnormal karyotype in a highly aggressive melanoma negative for telomerase activity
} Sarantis Gagos*1, George Papaioannou ${ }^{1,2}$, Maria Chiourea ${ }^{1}$, Sophie MerkLoretti $^{3}$, Charles-Edward Jefford ${ }^{4}$, Panagiota Mikou ${ }^{5}$, Irmgard IrmingerFinger ${ }^{4}$, Anna Liossi ${ }^{5}$, Jean-Louis Blouin ${ }^{3}$ and Sophie Dahoun ${ }^{3}$

\author{
Address: ${ }^{1}$ Division of Genetics, Biomedical Research Foundation of the Academy of Athens, Greece (BRFAA), ${ }^{2}$ Department of Gynecology, Laikon \\ Peripheral General University Hospital, Athens, Greece, ${ }^{3}$ Genetic Medicine, University Hospitals of Geneva, Geneva, Switzerland, ${ }^{4}$ Laboratory of \\ Molecular Gynecology and Obstetrics, Department of Gynecology and Obstetrics, Geneva University Hospitals, Geneva, Switzerland and \\ ${ }^{5}$ Department of Cytopathology, Laikon Peripheral General University Hospital, Athens, Greece \\ Email: Sarantis Gagos* - sgagos@bioacademy.gr; George Papaioannou - papaioannougk@ hotmail.com; \\ Maria Chiourea - mhiourea@bioacademy.gr; Sophie Merk-Loretti - Sophie.Merk@hcuge.ch; Charles-Edward Jefford - cejefford@hotmail.com; \\ Panagiota Mikou - kyttarologiko@laiko.gr; Irmgard Irminger-Finger - irmgard.irminger@medecine.unige.ch; \\ Anna Liossi - kyttarologiko@laiko.gr; Jean-Louis Blouin - jean-louis.blouin@medcli.unige.ch; Sophie Dahoun - Sophie.Dahoun@hcuge.ch \\ * Corresponding author
}

Published: 22 August 2008

Molecular Cytogenetics 2008, I:20 doi:10.1 186/1755-8166-I-20
Received: 20 June 2008

Accepted: 22 August 2008

This article is available from: http://www.molecularcytogenetics.org/content/I/I/20

(C) 2008 Gagos et al; licensee BioMed Central Ltd.

This is an Open Access article distributed under the terms of the Creative Commons Attribution License (http://creativecommons.org/licenses/by/2.0), which permits unrestricted use, distribution, and reproduction in any medium, provided the original work is properly cited.

\begin{abstract}
Malignant melanomas are characterized by increased karyotypic complexity, extended aneuploidy and heteroploidy. We report a melanoma metastasis to the peritoneal cavity with an exceptionally stable, abnormal pseudodiploid karyotype as verified by G-Banding, subtelomeric, centromeric and quantitative Fluorescence in Situ Hybridization (FISH). Interestingly this tumor had no detectable telomerase activity as indicated by the Telomere Repeat Amplification Protocol. Telomeric FlowFISH and quantitative telomeric FISH on mitotic preparations showed that malignant cells had relatively short telomeres. Microsatellite instability was ruled out by the allelic pattern of two major mononucleotide repeats. Our data suggest that a combination of melanoma specific genomic imbalances were sufficient and enough for this fatal tumor progression, that was not accompanied by genomic instability, telomerase activity, or the engagement of the alternative recombinatorial telomere lengthening pathway.
\end{abstract}

\section{Introduction}

Cutaneous malignant melanomas are highly aggressive tumors with unpredictable biological behavior [1]. Metastases in brain, bones and viscera with subsequent ascites development, are frequent [1]. The progression of a transformed melanocyte to malignant melanoma is accompanied by gradual acquisition of multiple genetic alterations that lead to losses of onco-suppressor genes and increased tumor hypermutability [2]. Malignant melanomas display both types of known genomic instability in neoplasia; chromosomal instability (CIN) and microsatellite instability (MIN) [2,3]. MIN has been observed in $30 \%$ of cutaneous malignant melanomas [4]. However, the great majority of malignant melanomas examined by various cytogenetic methods, exhibit increased karyotypic complexity, extended aneuploidy and heteroploidy [5-7]. Recurrent chromosomal imbalances in skin melanomas include losses of chromosomes $1 \mathrm{p}, 6 \mathrm{q}$ and $9 \mathrm{p}[2,8]$. 
Tumor progression and aggressive behavior have been associated with imbalances of chromosomes 7, 10 and 17 $[2,7]$.

Most human tumors including melanomas maintain sufficient telomere length for continuous growth by expressing telomerase $[9,10]$, the remainder are thought to utilize a variety of telomere recombination mechanisms termed alternative lengthening of telomeres (ALT) [11]. Observations on transformed and tumor cell lines that lack telomerase, linked ALT phenotype to highly increased structural chromosomal instability and extreme telomeric length deviation ranging from very long to extremely short telomeres [11]. We report a MIN, CIN, and TRAP negative (Telomere Repeat Amplification Protocol), highly aggressive melanoma metastasis to the peritoneal cavity, with unusually stable abnormal pseudodiploid karyotype, and relatively short but not dysfunctional telomeres.

\section{Methods}

\section{Immunochemistry-Cytopathology}

Cell material from the peritoneal aspirations was subjected to routine diagnostic cytopathology protocols including Giemsa, Papanicolaou, Hematoxylin-Eosin (BDH-Chemicals) stains and immunocytochemistry using the melanocyte specific antibody S-100 (Dako). Immunocytochemical staining against S-100 was performed using Horse Radish Peroxidase (HRP) (Dako). Cell smears were re-hydrated, treated with 3\% hydrogen peroxide for 15 minutes and rinsed with Tris Buffered Saline with $0.05 \%$ Tween 20 (Dako). After cooling for 20 min, sections were incubated with the primary antibody (rabbit antihuman monoclonal S-100 antibody, 1:400 dilution, Dako) for 1 hour at room temperature and then incubated for 45 min with an anti-mouse HRP labelled polymer (EnVision+System-HRP, Dako). Finally slides were treated with a diaminobenzidine (DAB) chromogenic substrate (Dako) for $10 \mathrm{~min}$, counterstained with hematoxylin, dehydrated and coverslipped.

\section{Short term cultures/Cytogenetic analysis}

Malignant cells from two peritoneal aspirations were collected by centrifugation $\left(10 \mathrm{~min} / 1500 \mathrm{rpm} / 25^{\circ} \mathrm{C}\right)$. They were subsequently cultured in eight $25 \mathrm{~cm}^{2}$ T-flasks at $37^{\circ} \mathrm{C}$ and $5 \% \mathrm{CO}_{2}$, in Dulbecco's Minimum Essential Medium supplemented with $10 \%$ fetal bovine serum, $0.08 \mathrm{mg} / \mathrm{ml}$ amphotericin, 25 units/ml penicillin, and 25 $\mathrm{pg} / \mathrm{ml}$ of streptomycin (Invitrogen). When high mitotic index was reached, cells were exposed to colcemid $(0.1$ $\mu \mathrm{g} / \mathrm{ml}$ ) (Invitrogen) for $30 \mathrm{~min}$, in $37^{\circ} \mathrm{C}$, and harvested using trypsine (Invitrogen), after $0.075 \mathrm{KCL}$ hypotonic treatment and Methanol/Acetic acid (BDH-Chemicals) fixation. For the construction of the representative karyotype, we combined G-Banding after Trypsine and Giemsa (GTG-Banding), inverted 4',6-diamidino-2-phenylindole
(DAPI)-banding, subtelomeric FISH (TeloVysion-Vysis) and telomeric FISH (Dako), in a total of 400 metaphases from 8 short term monolayer cell cultures. For dual-color interphase or metaphase FISH we used satellite probes specific for chromosomes 7 and 17 (Cytocell). In brief, our general FISH protocol was based on pepsin pre-treatment, formamide or $\mathrm{NaOH}$ target denaturation, overnight hybridization and high stringency post hybridization washes. Telomere-specific Peptide Nucleic acid Analog (PNA) hybridizations were performed using a Cy3(Indocarbocyanine)- conjugated (CCCTAA) $)_{3}$ probe (Dako), according to manufacturer's instructions. All FISH preparations were mounted and counterstained with VectaShield antifade medium (Vector), containing $0.1 \mu \mathrm{g} /$ ml DAPI (Sigma). GTG-Banding was performed after trypsine denaturation (Invitrogen) and Giemsa (BDH-Chemicals) staining. Digital images were captured in a Perceptive Systems Imaging, a Metasystems or an Applied Imaging molecular cytogenetics workstations equipped with fluorescent Zeiss, or Nikon microscopes. Quantification of telomeric PNA fluorescence was performed in 500 chromatids on DAPI counterstained metaphase preparations in a single hybridization experiment using the Isis software (Metasystems).

\section{Microsatellite instability assay}

Two mononucleotide markers, BAT-25 and BAT-26 were tested for microsatellite instability by radioactive PCR after Polyacrylamide Gel Electrophoresis (PCR-PAGE) assay, using the following primers: BAT25.1 (5'TCGCCTCCAAGAATGTAAGT-3'), BAT25.2 (5'-TCTGCATTTTAACTATGGCTC-3'), BAT26.1 (5'-TGACTACTTTTGACTTCAGCC-3') and BAT26.2 (5'AACCATTCAACATTTTTAACCC-3'). Experiment was monitored by controls for human microsatellite stability (normal genomic and MIN DNA from a patient with human Hereditary Non-Polyposis Colon Cancer HNPCC-).

\section{TRAP assay}

Telomerase activity of cell lysates was analyzed by the telomeric repeat amplification protocol (TRAP) assay with a TRAPeze Telomerase Detection kit (Intergen) according to manufacturer's instructions. Approximately $10^{6}$ cells were harvested and lysed in $400 \mu$ l of $1 \times$ CHAPS (3-[(3-Cholamidopropyl)dimethylammoniolpropanesulfonic acid, 3[(3-Cholamidopropyl)-dimethylammonio]-1-pro-

panesulfonate) lysis buffer [Tris- $\mathrm{HCl} 10 \mathrm{mM}, \mathrm{pH} 7.5 ; 1$ mM EGTA (ethylene glycol tetraacetic acid), $1 \mathrm{mM} \mathrm{MgCl}_{2}$, $0.5 \%$ CHAPS $10 \%$ glycerol, DEPC (Diethylpyrocarbonate) treated water on ice for $30 \mathrm{~min}$. Cell debris were spun down for 20 minutes at 12,000 r.p.m at $4^{\circ} \mathrm{C}$. Each reaction was carried out by using $2 \mu \mathrm{l}$ of supernatant, $1 \mu \mathrm{l}$ of each primer, $0.5 \mu \mathrm{l}$ of Taq-Polymerase (TAKARA), $10 \mu \mathrm{l}$ of solution-Q (Qiagen), $5 \mu$ l of $10 \times$ buffer, $2 \mu$ l of dNTPs, 
in DEPC treated water in final volume of $50 \mu \mathrm{l}$. The primers used for the TRAP-assay PCR, were TS-5'-AATCCGTCGAGCAGAGTT-3' and Cxa-5'-GTGTAACCCTAACCCTAA CCC-3'. The PCR program consisted first of an incubation at $30^{\circ} \mathrm{C}$ for $30 \mathrm{~min}$ and then in a thermocycler, $94^{\circ} \mathrm{C}$ for $2 \mathrm{~min} ; 94^{\circ} \mathrm{C}$ for $30 \mathrm{~s}, 50^{\circ} \mathrm{C}$ for $25 \mathrm{~s}, 72^{\circ} \mathrm{C}$ for $30 \mathrm{~s}(33 \times)$; $72^{\circ} \mathrm{C}$ for $1 \mathrm{~min}$. PCR products were electrophoresed in a 10\% 19:1 acrylamide gel (Sigma)/0.5× TBE (Tris/Borate/ EDTA) buffer using the mini protean II gel system (Biorad). Gels were stained with $2 \mu$ l of SYBR Green (Sigma) for $15 \mathrm{~min}$ at room temperature in $50 \mathrm{ml}$ of TBE $0.5 \times$ buffer, and then exposed to UV light and visualized by a Kodak image acquisition station.

\section{Flow FISH}

To measure cellular telomere length, short term cultured cells were hybridized in situ with a fluorescent telomerespecific peptide nucleic acid probe, according to manufacturer's protocol. Briefly, cells were washed in PBS, and resuspended to $10^{5}$ cells $/ 100 \mu \mathrm{l}$ of a hybridization mixture (Dako) containing 70\% formamide and a telomere-specific FITC (Fluorescein isothiocyanate)-conjugated PNA probe. Control samples were re-suspended in hybridization solution without probe to obtain background fluorescence values. After hybridization, cells were spun down and washed twice with $4 \mathrm{ml}$ PBS (Phosphate Buffered Saline) at $40^{\circ} \mathrm{C}$ for $10 \mathrm{~min}$ and finally re-suspended in PBS containing 0.1\% Bovine Serum Albumin, $10 \mu \mathrm{g} / \mathrm{ml}$ RNase A (Roche) and $0.1 \mu \mathrm{g} / \mathrm{ml}$ propidium iodide (Calbiochem-Novabiochem). Cells were analyzed on a FACScan flow cytometer (Becton Dickinson) or stored at $4{ }^{\circ} \mathrm{C}$ before analysis.

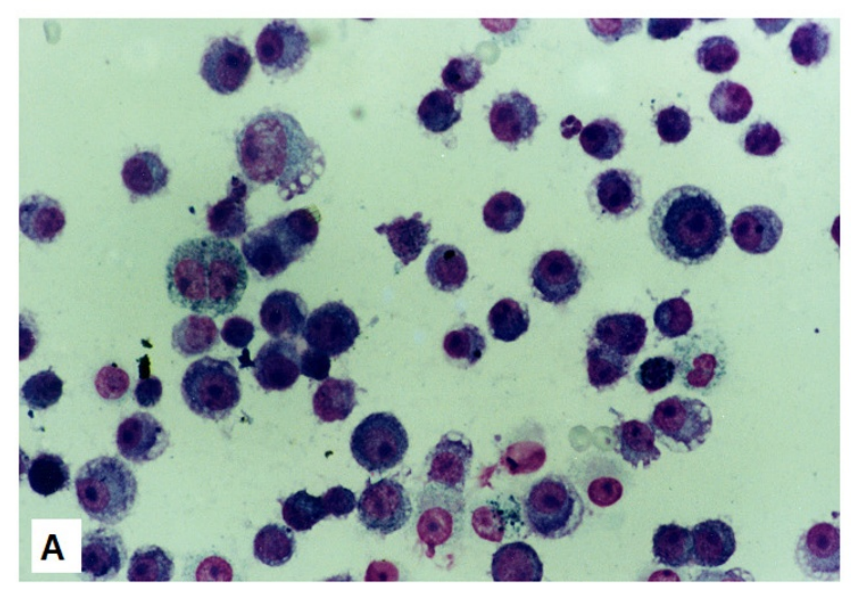

\section{Results}

\section{Patient history and ascitic fluid samples}

Peritoneal fluid samples were obtained by two subsequent paracenteses (within a 12-day interval) of a 38-yearold woman, presented at the Department of Gynecology, Laikon Hospital, with ascites and solid structures at her ovaries as revealed by CT-scan. Two years ago the patient had a less than $1.5 \mathrm{~cm}$ large, cutaneous nevus excised from the anterior surface of her left hip. The primary tumor was characterized as a nodular melanoma, Clark's level 3, Breslow's depth $2.0 \mathrm{~mm}$. One out of 14 inguinal nodes, excised in a subsequent operation, was found to be invaded. She received 6 cycles of chemotherapy (cis-platin-dacarbazine) and remained disease-free for 15 months. The cytologic examination of the ascitic aspiration confirmed the presence of malignant cells positive for the melanocyte specific antibody S-100 (Figure. 1). The patient refused to be operated, gave her written consent for further research on the specimens obtained, and expired 40 days after presentation.

\section{Cytogenetic analysis}

G-Banding analysis (according to ISCN 1995) [12] from 8 short-term cell cultures of two peritoneal aspirations taken in an interval of 12 days, showed a 46,XX,del(6)(q23?qter), del(9)(p10pter), der(10)t(7;10)( q31.3qter::p13)del(10)(p14?pter), der(11)t(5;11)(q22.3 qter;q23)del(11)(q24?qter),i(17q) pseudodiploid karyotype, in $94-96 \%$ of 200 mitoses examined (Figure. 2A). Endoreduplication was observed in $4-6 \%$ of the malignant cells leading to a $92, \mathrm{XXXX}$, idemx2 karyotype. Subtelomeric FISH specific for all human telomeres except for chromosomes 16, 19, 20 and the short arms of acrocentric chromosomes, was used to assist in the description of

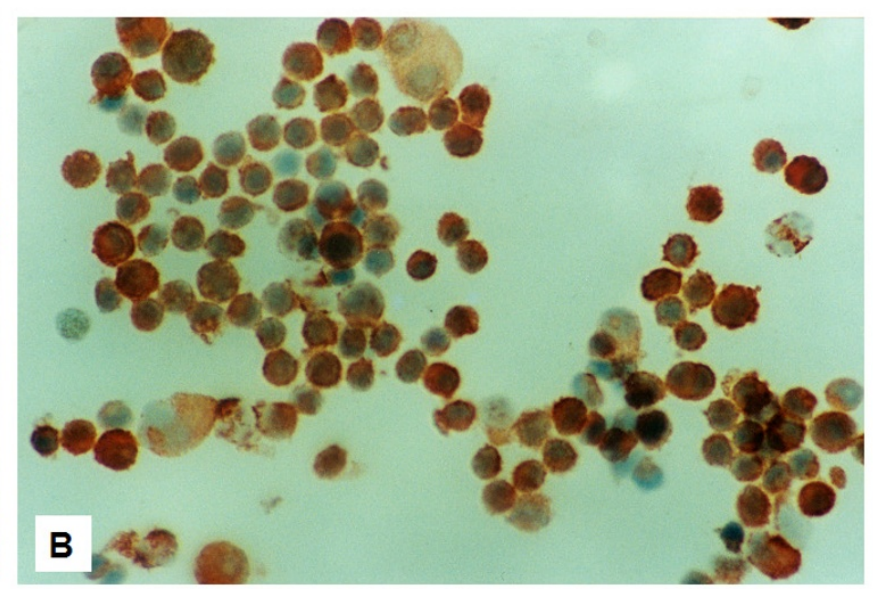

Figure I

The cytologic examination of the ascitic fluid showed malignant cells with high mitotic index (Giemsa $\times 400)$ (A). Immunocytochemistry against the melanocyte specific antibody S-I00 confirmed the presence of malignant melanocytes (Hematoxylin and DAB $\times$ 400). 
A
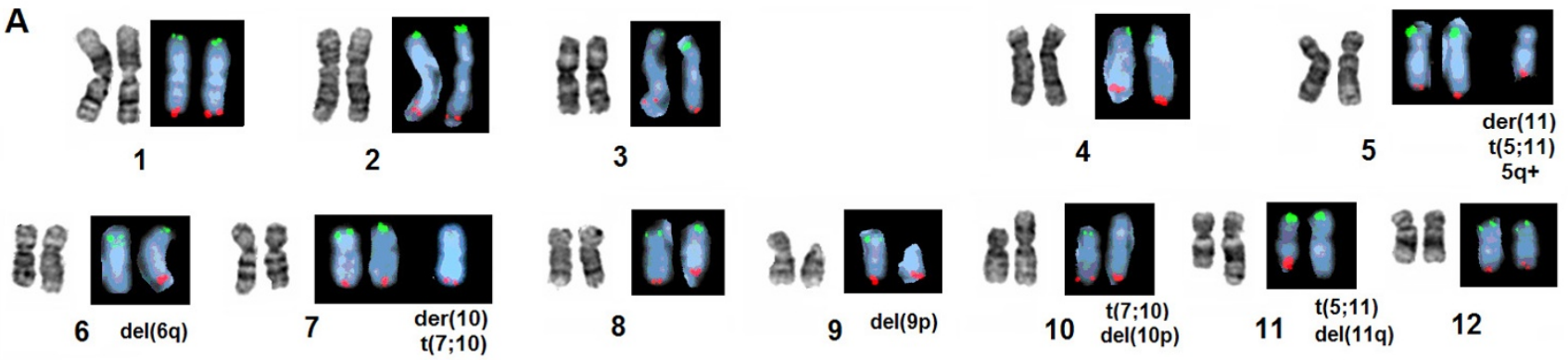

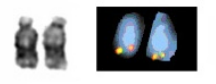

13

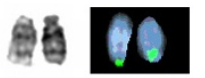

14

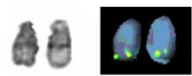

15

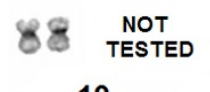

19

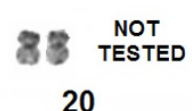

20

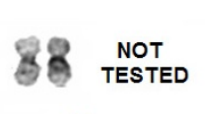

16

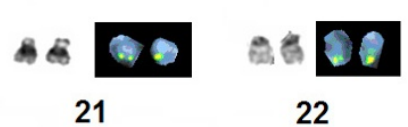

B Interphase dual-color centromere specific FISH
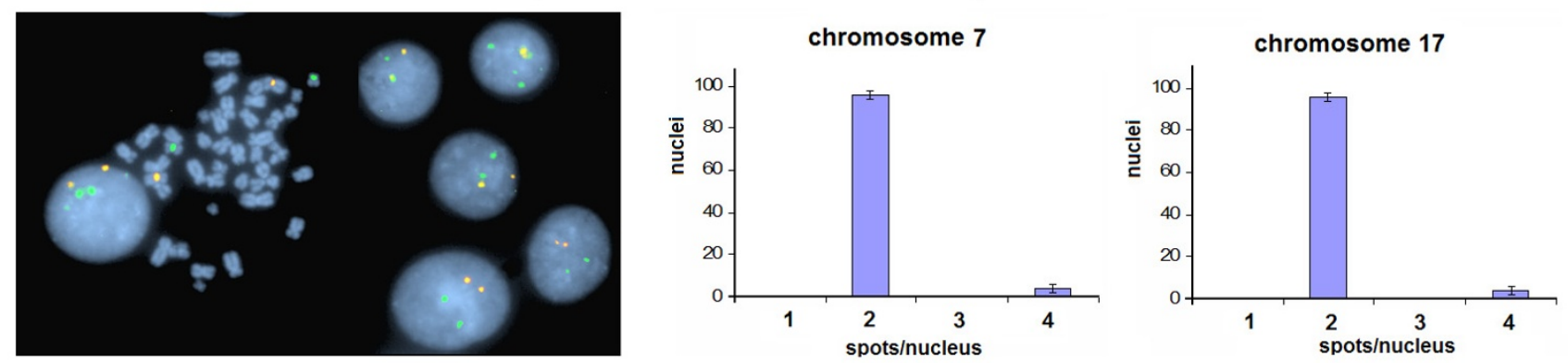

\section{Figure 2}

A GTG-Banding and sub-telomere specific FISH composite representative karyotype of the reported melanoma. Subtelomeric FISH verified structural integrity of most chromosomes, canonical orientation of both translocations, the deletions $6 \mathrm{q}, 10 \mathrm{p}$, and I Iq, as well as the isochromosome $\mathrm{i}(\mathrm{I7q})$. The depicted partial dual or triple color subtelomeric FISH karyotypes derive from 23 independent pseudodiploid metaphases; each black box represents a single mitotic nucleus $($ Red $=$ Spectrum Orange, Green $=$ FITC, Purple $=$ Spectrum Aqua $\times 1000)(A)$. Dual color interphase FISH for centromeres 7 (yellow), and 17 (green), shows remarkable numerical stability in 200 nuclei (error-bars represent the standard error of the mean) (B).

marker chromosomes identified by G-Banding (Figure. $2 \mathrm{~A})$, and to verify deletions spanning up to the end of rearranged chromosomes. To examine if this remarkable karyotypic stability was not confined only to dividing mitotic cells, we performed dual color interphase FISH with probes specific for centromeres 7 and 17, in 200 interphase nuclei obtained from 2 short-term cell cultures from both aspirations. Centromeres 7 and 17 showed notable numerical stability in these populations. The rates of whole genome endoreduplication were similar to those of the karyotyped mitotic cells (Figure. 2B).

\section{Examination of factors related to chromosome stability} In an attempt to attribute the karyotypic stability of this metastatic melanoma to measurable parameters related to chromosome stability in the context of neoplastic contin- uous growth, we examined microsatellite instability (MIN) and telomerase activity. Microsatellite unstable tumors show a significantly lower rate of chromosomal instability as compared to the MIN negative [3]. To rule out underlying microsatellite genomic instability in this metastatic melanoma, we tested by PCR-PAGE the robust mononucleotide repeat markers BAT-25 and BAT-26. Both loci have been shown to be sensitive markers of MIN [13]. Compared to positive and negative controls, this metastatic melanoma displayed no micro-satellite instability (Figure. 3A). Ectopic expression of telomerase in normal fibroblasts has been connected to karyotypic stability [14]. We conducted a TRAP assay to test telomerase activity in cultured cells from 2 sub-cultures from both peritoneal aspirations. In both samples this assay was negative (Figure. 3B). To examine if these melanoma cells fol- 
A BAT25

MIN control melanoma $(+)(-)$
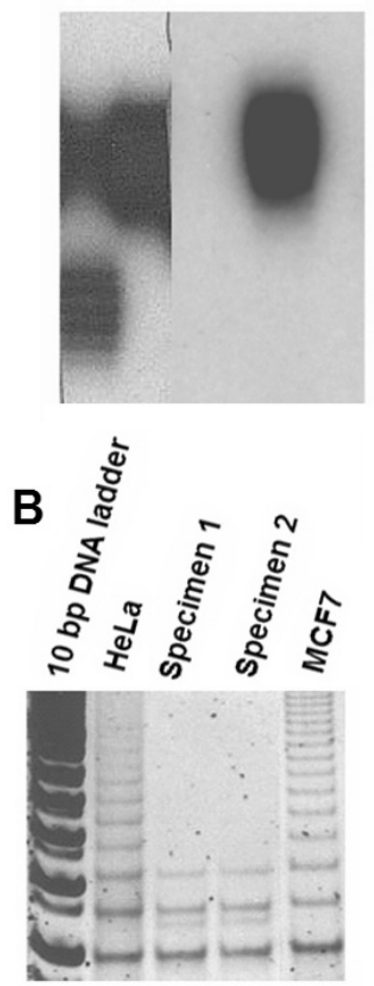

BAT26

MIN control melanoma

$(+)(-)$

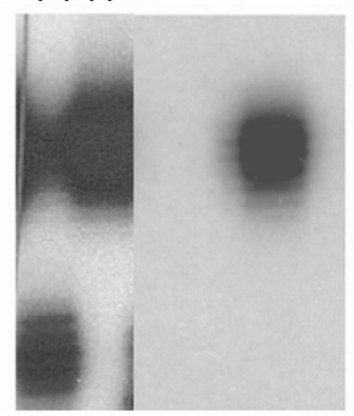

C

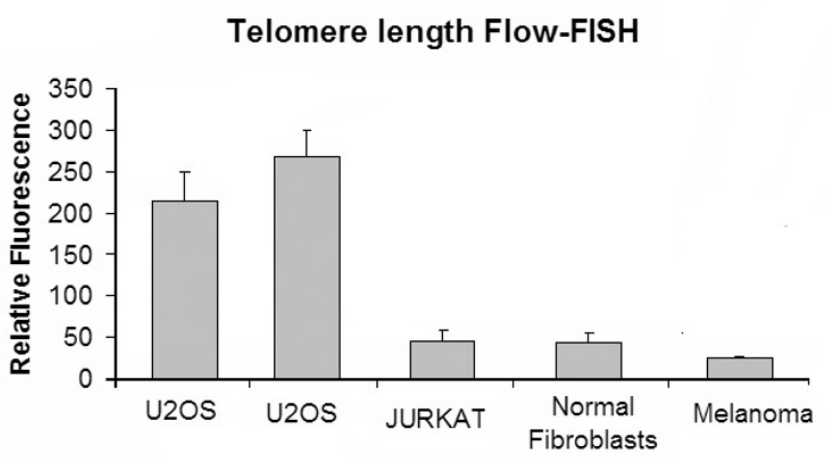

D PNA Telomeric Quantitative FISH

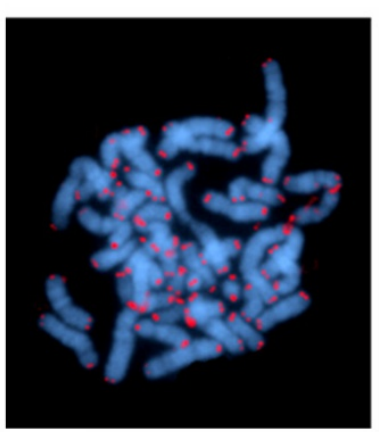

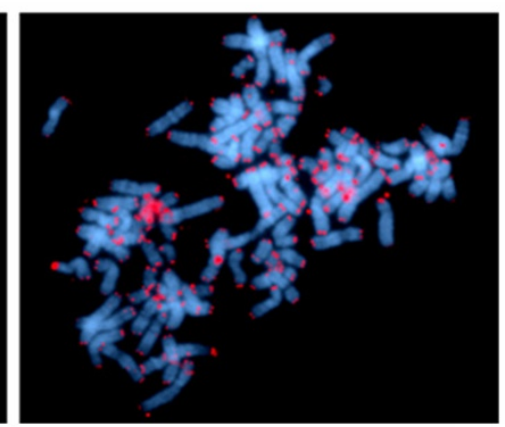

Telomere length $\mathrm{n}=500$ chromatids

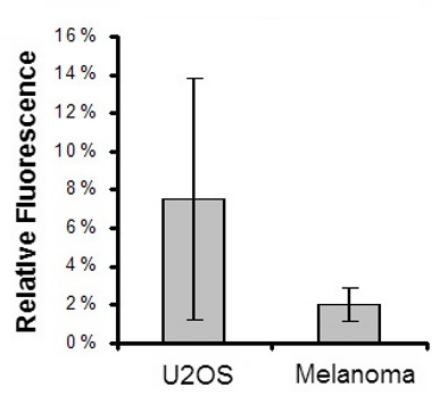

Figure 3

Microsatellite instability in neoplasia (MIN) was excluded in this tumor since the microsatellite markers BAT-25 and BAT-26, showed no instability as compared to MIN positive and negative controls (A). The TRAP assay was negative for telomerase activity in cell culture material obtained from both peritoneal aspirations as compared to two well known telomerase positive human cancer cell lines (MCF-7 and HeLa) (B). Telomere length in this melanoma is relatively low as compared to the ALT U2OS cell line, leukemic JURKAT cells and human embryonic fibroblasts (error bars represent standard error of the mean between 3 independent experiments) (C). Telomeric PNA FISH indicated uniform terminal capping with TTAGGG repeats on virtually all chromosomes in both pseudodiploid and endoreduplicated clones and low deviation of telomeric length in 500 chromatids as compared to the ALT U2-OS cell line (inverted DAPIxI000) (error bars represent standard deviation)(D).

lowed the ALT-pathway of telomere maintenance [11] we compared the relative telomeric length of our specimen by Quantitative-PNA-Flow-FISH [15] with the pseudodiploid human acute T cell leukemia JURKAT cell line, normal human fibroblasts and an ALT-positive cell line [16]. Cell material for this test was obtained from a short-term subculture that was previously karyotyped and found to be composed exclusively from chromosomally abnormal mitotic cells. This comparison revealed that the melanoma cells had relatively short telomeres (Figure. 3C). PNA-telomeric FISH on 500 chromatids from 10 randomly picked metaphase spreads showed that most of the 46 chromosomes of this metastatic melanoma were uniformly capped with telomeric repeats (Figure. 3D) and no signs of structural chromosome instability attributed to telomere dysfunction such as end-to-end fusions and dicentric chromosomes were evident.

\section{Discussion}

Metastatic transition in most human tumors is accompanied by a series of complex recurrent and stochastic chromosomal anomalies. These changes reflect the evolutionary pressure held by the cancer cells to bypass natural barriers and re-establish continuous growth into unrelated histopathologic environments $[17,18]$. In this report, the karyotype of the primary tumor is not available, therefore the relative simplicity of genomic imbalances encountered in metastasis, permits only a 
hypothetical reconstruction of the chromosomal evolution of the disease. It has been proposed that melanomas develop through a mode of karyotypic evolution, common to both low and high complexity karyotypes [2]. To become malignant, an apparently normal melanocyte of this patient underwent multiple karyotypic alterations involving breakpoints in at least 7 different chromosomes as well as chromosomal losses and non-disjunctions. Although we cannot define the temporal order of the recorded rearrangements, we postulate that the hemizygous deletions 6q23qter and 9p- might be early events in the chromosomal evolution of this melanoma. Translocations and deletions involving the q-arm of human chromosome 6 have been found in more than $80 \%$ of melanomas [5]. According to Hoglund et al (2005) [19], deletions of the distal 6q should be considered early chromosomal lesions in melanomas. Moreover, the short arm of chromosome 9 is the site of several cell cycle regulators that have been linked with familial disease, or associated to melanoma progression and aggressive behavior [2]. The gains of genomic material and the additional deletions involving $10 p, 11 q$ and $17 p$, were byproducts of unbalanced chromatid separation of balanced translocations and the isochromosome formation. These more complex alterations might represent later events in the process of the karyotypic evolution of the disease. Chromosomes 10 and 11 are frequently lost in metastatic melanomas whereas chromosome 7 is frequently gained $[2,5,7,20,21]$.

Rearrangements affecting the short arm of chromosome 17 , where the $\mathrm{p} 53$ gene is located, have been implicated in the pathogenesis of malignant melanoma [2]. It is interesting that although p53 deficiency has been related to increased rates of numerical chromosome instability or polyploidy [22], in this melanoma hemizygosity of p53 was not associated with continuous genomic instability. MIN tumors display extremely low rates of CIN [3]. We ruled-out the possibility that this melanoma belonged to this type of tumors. We also ruled-out CIN in our specimens, since this metastatic pseudodiploid tumor was highly cytogenetically stable by all means examined. These results are compatible with those of Abdel-Rahman et al. 2001 and Fabarius et al. 2003, who observed that chromosomes of near-diploid cells are structurally much more stable than those of highly aneuploid counterparts $[23,24]$. Perhaps, the rare, melanoma described here, is unusually stable, because it is near-diploid, in contrast to the majority of highly aneuploid genomically unstable melanomas.

The majority of human malignant melanomas and melanoma cell lines studied with the TRAP assay were found to express telomerase activity $[10,25]$. Furthermore, telomerase activity has been connected to aggressiveness of melanomas [26]. In continuous neoplastic growth, insufficiently protected telomeres tend to undergo end-toend fusions and to produce numerous complex chromosome rearrangements such as dicentric chromosomes and inverted duplications [27-29]. No evidence of such lesions was found in our specimens. The transient stage of structural chromosomal instability in this case, equally involved subtelomeric, centromeric and genomic regions, and gave rise to translocations with canonical orientation. Surprisingly, this metastatic tumor was negative for telomerase activity. Moreover, no signs of recombinatorial telomere elongation were present [11] since flow FISH showed relatively short telomeres and PNA FISH displayed a uniform terminal capping of virtually all chromosomes of this melanoma with TTAGGG repeats.

The remarkable stability, and telomeric integrity of the metastatic tumor presented here, can be attributed either to transient telomerase activation, or the action of an unknown but efficient telomere restoration mechanism. However, we can not exclude the possibility that adequate telomeric length for clonal expansion and metastasis was already acquired by the cancer progenitor melanocyte. This assumption might correlate with the relatively young age of the patient. A thorough examination of a series of human osteosarcomas revealed a category of tumors that do not express telomerase activity and do not display any ALT-pathway characteristics [30]. Interestingly these tumors showed low rates of CIN [30]. A similar sub-category might be also encountered in melanomas. The exceptional case reported here, suggests that metastatic progression in this melanoma, was not accompanied by genomic instability, telomerase activity, or the engagement of the classical alternative recombinatorial telomere lengthening (ALT) pathway.

\section{Competing interests}

The authors declare that they have no competing interests.

\section{Authors' contributions}

SG conceived and coordinated the study, carried out the analysis of the results and wrote the manuscript. GP collected the samples, acquired informed consent and took part in the analysis of results and manuscript preparation. MC carried out conventional and FISH cytogenetics. SM-L carried out subtelomeric FISH. C-EJ performed the TRAP and Flow-FISH assays. PM and AL carried out and analyzed the cytopathology assays. II-F participated in the design of the study. J-LB performed and analyzed the microsatellite instability assays. SD participated in coordination of the study and analysis of results. All authors read and approved the final manuscript.

\section{Acknowledgements}

We thank M. Morris for providing reagents. This work was supported by the Biomedical Research Foundation of the Academy of Athens Greece 
(BRFAA), in a starting intramural funding and the Grant\#05NON-EU-449 of the Greek Secretariat of Research of the Greek Ministry of Development to SG.

\section{References}

I. Rhodes AR: Cutaneous melanoma and intervention strategies to reduce tumor-related mortality: what we know, what we don't know, and what we think we know that isn't so. Dermatol Ther 2006, 19:50-69.

2. Hussein MR: Genetic pathways to melanoma tumorigenesis. I Clin Pathol 2004, 57:797-80I.

3. Lengauer C, Kinzler W, Vogelstein B: Genetic instabilities in human cancers. Nature 1998, 396:643-649.

4. Hussein MR, Sun M, Tuthill RJ, Roggero E, Monti JA, Sudilovsky EC, Wood GS, Sudilovsky O: Comprehensive analysis of $1 / 2$ melanocytic skin lesions demonstrates microsatellite instability in melanomas and dysplastic nevi, but not in benign nevi. J Cutan Pathol 200I, 28:343-350.

5. Thompson FH, Emerson J, Olson S, Weinstein R, Leavitt SA, Leong SP, Emerson S, Trent JM, Nelson MA, Salmon SE, et al.: Cytogenetics of I 58 patients with regional or disseminated melanoma. Subset analysis of near-diploid and simple karyotypes. Cancer Genet Cytogenet 1995, 83:93-104.

6. Schulten H], Gunawan B, Otto F, Hassmann R, Hallermann C, Noebel A, Fuzesi L: Cytogenetic characterization of complex karyotypes in seven established melanoma cell lines by multiplex fluorescence in situ hybridization and DAPI banding. Cancer Genet Cytogenet 2002, I33:134-141.

7. Hoglund M, Gisselsson D, Hansen GB, White VA, Sall T, Mitelman F, Horsman D: Dissecting karyotypic patterns in malignant melanomas: temporal clustering of losses and gains in melanoma karyotypic evolution. Int / Cancer 2004, 108:57-65.

8. Bastian BC, Olshen AB, LeBoit PE, Pinkel D: Classifying melanocytic tumors based on DNA copy number changes. Am J Pathol 2003, 163:1765-1770.

9. Kim NW, Piatyszek MA, Prowse KR, Harley CB, West MD, Ho PLC, Coviello GM, Wright WE, Weinrich SL, Shay JW: Specific association of human telomerase activity with immortal cells and cancer. Science 1994, 266:2011-2015.

10. Carvalho L, Lipay M, Belfort F, Santos I, Andrade J, Haddad A, Brunstein F, Ferreira L: Telomerase activity in prognostic histopathologic features of melanoma. J Plast Reconstr Aesthet Surg 2006, 59:96|-968.

II. Muntoni A, Reddel RR: The first molecular details of ALT in human tumor cells. Human Molecular Genetics 2005, 14:191-196.

12. ISCN: An international system for human cytogenetic nomenclature. Edited by: Mitelman F. Basel: S. Karger; 1995.

13. Papadopoulos N, Nicolaides NC, Liu B, Parsons R, Lengauer C, Palombo F, D'Arrigo A, Markowitz S, Willson JKV, Kinzler KW, Jiricny J, Vogelstein B: Mutations of GTBP in genetically unstable cells. Science 1995, 268:1915-1917.

14. Morales CP, Holt SE, Ouellette M, Kaur KJ, Yan Y, Wilson KS, White MA, Wright WE, Shay JW: Absence of cancer-associated changes in human fibroblasts immortalized with telomerase. Nat Genet 1999, 2 I:II5-I I8.

15. Baerlocher GM, Mak J, Tien T, Lansdorp PM: Telomere length measurement by fluorescence in situ hybridization and flow cytometry: tips and pitfalls. Cytometry 2002, 47:89-99.

16. Scheel C, Schaefer KL, Jauch A, Keller M, Wai D, Brinkschmidt C, van Valen F, Boecker W, Dockhorn-Dworniczak B, Poremba C: Alternative lengthening of telomeres is associated with chromosomal instability in osteosarcomas. Oncogene 2001, 20:3835-3844.

17. Nowell PC: The clonal evolution of tumor cell populations. Science 1976, 194:23.

18. Gagos S, Irminger-Finger I: Chromosome instability in neoplasia: chaotic roots to continuous growth. Int J Biochem Cell Biol 2005 37:1014-1033.

19. Hoglund M, Frigyesi A, Sall T, Gisselsson D, Mitelman F: Statistical behavior of complex cancer karyotypes. Genes Chromosomes Cancer 2005, 42:327-34l.

20. Hussein MR, Sun M, Roggero E, Sudilovsky EC, Tuthill RJ, Wood GS, Sudilovsky O: Loss of heterozygosity, microsatellite instability, and mismatch repair protein alterations in the radial growth phase of cutaneous malignant melanomas. Mol Carcinog 2002, 34:35-44

21. Stark M, Hayward N: Genome-wide loss of heterozygosity and copy number analysis in melanoma using high-density singlenucleotide polymorphism arrays. Cancer Res 2007, 67:2632-2642.

22. Liu G, Parant JM, Lang G, Chau P, Chavez-Reyes A, El-Naggar AK, Multani A, Chang S, Lozano G: Chromosome stability, in the absence of apoptosis, is critical for suppression of tumorigenesis in Trp53 mutant mice. Nat Genet 2004, 36:63-68.

23. Abdel-Rahman WM, Katsura K, Rens W, Gorman PA, Sheer D, Bicknell D, Bodmer WF, Arends MJ, Wyllie AH, Edwards PA: Spectral karyotyping suggests additional subsets of colorectal cancers characterized by pattern of chromosome rearrangement. Proc Natl Acad Sci USA 200I, 98:2538-2543.

24. Fabarius A, Hehlmann R, Duesberg $\mathrm{PH}$ : Instability of chromosome structure in cancer cells increases exponentially with degrees of aneuploidy. Cancer Genet Cytogenet 2003, I 43:59-72.

25. Parris CN, Jezzard S, Silver A, MacKie R, McGregor JM, Newbold RF: Telomerase activity in melanoma and non-melanoma skin cancer. Br J Cancer 1999, 79:47-53.

26. Glaess A, Bosserhoff AK, Buettner R, Hohenleutner U, Landthaler M, Stolz W: Increase in telomerase activity during progression of melanocytic cells from melanocytic naevi to malignant melanomas. Arch Dermatol Res 1999, 291:81-87.

27. Murnane JP, Sabatier L, Marder BA, Morgan WF: Telomere dynamics in an immortal human cell line. EMBO J 1994, I 3:4953-4962.

28. Gisselsson D, Pettersson L, Hoglund M, Heidenblad M, Gorunova L, Wiegant J, Mertens F, Dal Cin P, Mitelman F, Mandahl N: Chromosomal breakage-fusion-bridge events cause genetic intratumor heterogeneity. Proc Natl Acad Sci USA 2000, 97:5357-5362.

29. de Lange T: Shelterin: the protein complex that shapes and safeguards human telomeres. Genes Dev 2005, I9:2100-21 I0.

30. Johnson JE, Gettings EJ, Schwalm J, Pei J, Testa JR, Litwin S, von Mehren M, Broccoli D: Whole-genome profiling in liposarcomas reveals genetic alterations common to specific telomere maintenance mechanisms. Cancer Res 2007, 67:9221-9228.
Publish with Bio Med Central and every scientist can read your work free of charge

"BioMed Central will be the most significant development for disseminating the results of biomedical research in our lifetime. "

Sir Paul Nurse, Cancer Research UK

Your research papers will be:

- available free of charge to the entire biomedical community

- peer reviewed and published immediately upon acceptance

- cited in PubMed and archived on PubMed Central

- yours - you keep the copyright 